\title{
Phillip D. Wilson, Jr., MD: A Life Fulfilled
}

\author{
Charles N. Cornell, MD
}

Received: 29 July 2016/Accepted: 29 July 2016/Published online: 15 August 2016

(C) Hospital for Special Surgery 2016

With awe and reverence I note the passing of Philip Wilson, Jr., MD. As with everything in his recent life, he accomplished this with great dignity in the peace and comfort of his beloved home. He was working right until he no longer could on a project which will provide a legacy for all of us who practice total hip replacement. He was completing the 40-year follow-up study of his original series of patients. It was my privilege to be asked to assist him. The contribution of his study will be that his focus was directed at the quality of life that his patients recovered following the surgery. He realized that total hip replacement dramatically improves a patient's quality of life that can maintain throughout the patient's lifetime. If the prosthesis fails, the surgery is not a failure because revision surgery can restore and maintain the improved quality of life. His work suggests that need for revision does not imply a failure of the arthroplasty because with revision the original benefit of the primary hip replacement can be restored.

This focus on the patient typifies Dr. Wilson's approach to surgery. In teaching a generation of orthopedic residents, Dr. Wilson emphasized that technical mastery of surgery was, of course, mandatory but care of the patient was paramount. Consistently dedicated patient care was his mantra and practice. Those of us lucky enough to be in his shadow had the opportunity to observe the benefit of his approach. We learned directly from him that if you provided persistent, personal care in spite of setbacks and complications, nearly any orthopedic challenge could be brought to a favorable conclusion.

Until recently, Dr. Wilson continued to see patients carefully documenting their function and satisfaction with their hip replacements. Over the past several months, his mind remained clear but his frailty increased. He remained eager to complete his 40-year study and be sure that we would complete the task, if necessary, without him. With his passing, our commitment to honor his wish is felt with greater urgency.

Our gratitude is infinite. He gave more than we should have expected. The HSS he built has become that light shining upon the hill. We can miss him or better yet, keep that light shining brighter still.

\section{Compliance with Ethical Standards}

Conflict of Interest: Charles N. Cornell, MD has declared that he has no conflict of interest.

Human/Animal Rights: This article does not contain any studies with human or animal subjects performed by the any of the authors.

\section{Informed Consent: N/A}

Required Author Forms Disclosure forms provided by the authors are available with the online version of this article. 